\title{
Carnitine Ester Measurement
}

National Cancer Institute

\section{Source}

National Cancer Institute. Carnitine Ester Measurement. NCI Thesaurus. Code C147323.

The determination of the amount of carnitine ester present in a sample. 